\title{
De como iluminar no projeto Palco Giratório: um relato errante sobre a aprendizagem em iluminação cênica
}

How to illuminate in the project Palco Giratório: a wandering story about of the learning in stage lighting

José Jackson Silva ${ }^{1}$ 


\section{Resumo}

Neste trabalho busco refletir sobre o processo de aprendizagem em Teatro, em geral, e sobre o aprendizado em iluminação cênica, em especial, a partir da experiência de uma turnê nacional no projeto Palco Giratório, ocasião na qual pude vivenciar as contradições, conflitos e dificuldades em iluminar um espetáculo teatral em 43 cidades distintas pelas cinco regiões do país. Constatando, na prática, que o objetivo diário de um agente da cena, que se aventura nos palcos brasileiros, é a capacidade genuína de aprender a aprender.

Palavras-chave: Iluminação cênica; arte-educação; pedagogia; teatro

\section{Abstract}

In this work, I intend to reflect on the learning process in Theater, in general, and on learning in stage lighting, in especially, from the experience of a national tour of the Palco Giratório project, at which time I was able to experience the contradictions, conflicts and difficulties in illuminating a theatrical spectacle in 43 different cities across the five regions of the country. Realizing, in practice, that the daily goal of an agent of the scene, who ventures on Brazilian stages, is the genuine ability to learn to learn.

Keywords: Stage lighting; art-education; pedagogy; theater 
Introdução

O melhor aprendiz não é aquele que aborda o mundo através de hábitos cristalizado, mas aquele que consegue permanecer sempre em processo de aprendizagem.

(Virginia Kastrup, 1999)

Em 2014 eu tive uma experiência muito impactante como artista e aprendiz das artes cênicas: fui convidado, às pressas, para fazer a luz do espetáculo Sargento Getúlio ${ }^{2}$ durante a turnê do projeto Palco Giratório ${ }^{3}$ (SESC), para o qual o grupo Teatro $\mathrm{Nu}^{4}$, sob direção de Gil Vicente Tavares, da cidade de Salvador (BA), foi um dos selecionados. Neste convite estava implícito iluminar as apresentações do espetáculo solo de um dos principais atores do teatro baiano, em atividade, Carlos Betão ${ }^{5}$, durante 9 meses, em 43 cidades, nas cinco regiões do país. Detalhe: eu não fui o criador do projeto de iluminação e não tinha operado a luz desse espetáculo, até então. Havia prestigiado como espectador na sua estreia há uns dois anos antes, mas nem sequer cogitei a possibilidade de vir a compor a equipe, por já estar envolvido em outros projetos, e por perceber a solidez e comprometimento da equipe com o espetáculo.

Com grupo Teatro Nu eu já tinha trabalho como assistente de direção no espetáculo Os javalis, ${ }^{6}$ no ano de 2008, ocasião na qual pude estar bem próximo à equipe e acompanhar o desenvolvimento do espetáculo. Porém, não era um membro oficial do grupo. Somado a isso, durante a criação do Sargento Getúlio eu estava focado em finalizar minha graduação em direção teatral, bem como, em dar continuidade as oficinas, aulas e seminários sobre iluminação cênica com profissionais respeitados no meio artístico, como Jorginho de Carvalho. Ao integrar o projeto de extensão "ações técnico-artísticas no âmbito do espetáculo" da Escola de Teatro da UFBA, que tinha por objetivo ser um laboratório de práticas dos fundamentos técnicos do espetáculo, dentre eles a criação, montagem e operação de luz, entre 2008 e 2011, período em

\footnotetext{
${ }^{2}$ Elenco: Carlos Betão. Direção e versão teatral: Gil Vicente Tavares. Assistência de direção: Clarissa Rebouças. Trilha Sonora: Ivan Bastos. Voz: Manuela Rodrigues / violino: Mário Soares. Cenografia: Rodrigo Frota. luminação: Eduardo Tudella. Preparação corporal: Mell Borba. Pintura "Luzinete": Sante Scaldaferri. Contra-regra: Anderson Alan design gráfico: Guto Chaves. Produção: Multi Planejamento Cultural. Assessoria de imprensa: Frente \& Verso Comunicação Integrada fotografias do site: Adenor Gondim. Fonte: http://www.teatronu.com/sargento-getulio/

${ }^{3}$ Para difundir as artes cênicas brasileiras e democratizar o acesso à cultura, o Palco Giratório (SESC) proporciona mais que entretenimento. 0 projeto possibilita trocas de experiências e intercâmbios entre artistas e a plateia, valorizando sempre a educação e cidadania dos espectadores. Há 15 anos circulando pelo pais, o Palco Giratório busca caminhos além do eixo- sul-sudeste para difundir a cultura onde o teatro puder chegar. (Disponível em http://www.sesc.com.br/palcogiratorio)

${ }^{4}$ Em agosto de 2011, o Teatro NU estreou seu primeiro monólogo, fazendo a abertura do Festival Bahia em Cena e comemorando os cinco anos do grupo. Sargento Getúlio, a partir da obra homônima de João Ubaldo Ribeiro, que esteve presente na estria, comemorou também os setenta anos do autor e os quarenta anos de publicação da obra. Fonte: http://www.teatronu.com/sargento-getulio/

${ }^{5}$ Formado em Interpretação Teatral pela Escola de Teatro da UFBA, vem atuando em alguns dos principais trabalhos teatrais da Bahia nos últimos anos. Por cinco vezes, foi selecionado pelo Núcleo do Teatro Castro Alves, trabalhando com diretores de renome nacional, como Gabriel Vilela e Francisco Medeiros. Duas vezes indicado como melhor ator coadjuvante pelo Prêmio Braskem de Teatro pelas peças Baal (Bertold Brecht/direção: Harildo Deda) e A Vida de Galileu (Bertold Brecht/direção: Elisa Mendes). Podemos destacar ainda na área de teatro as peças: O Sonho (Strindberg/direção: Gabriel Vilela), Os Iks (Higgins e Cannon/direção: Francisco Medeiros), Hamlet (Willian Shakespeare/direção: Harildo Deda), Calígula (Camus/direção: Fernando Guerreiro) e O Casamento do Pequeno Burguês (Bertold Brecht/direção: Luiz Marfuz). Em 2011, estreou seu primeiro monólogo o espetáculo Sargento Getúlio. Com este trabalho, ganhou o Prêmio Braskem de Melhor Ator e Melhor Espetáculo. Fonte: http://www.teatronu.com/carlos-betao/

${ }^{6}$ Os javalis é a segunda montagem do Teatro NU. Inspirado livremente na peça O rinoceronte, de Eugene lonesco. Texto e direção: Gil Vicente Tavares; Assistência de direção: José Jackson; Elenco: Carlos Betão e Marcelo Praddo; Cenário e figurino: Euro Pires; lluminação: Eduardo Tudella; Trilha e efeitos sonoros: Luciano Bahia; Cenotécnicos: Nahuel Di Renzo e Adriano Passos; Operador de luz: Bruno Berzot; Contra-regra: Anderson Alan; Imagem do javali: Gaio; Programação visual: Ana Paula Vasconcelos; Fotos: Jônathas Araujo;Assessoria de imprensa: Jussilene Santana; Produção: As Três Produções e Fernanda Bezerra. Fonte: http://www.teatronu.com/os-javalis/
} 
que estudei e trabalhei com muitos artistas, técnicos e iluminadores da cidade de Salvador (BA), me distanciando, assim, dos trabalhos do coletivo cênico mencionado.

No entanto, quando o convite chegou, por meio do diretor do grupo e pela força do acaso- o operador responsável pelo espetáculo havia tomado posse em um cargo público e não poderia mais viajar- o ímpeto foi maior que a consciência da enrascada que estava por vir. Prontamente, aceitei o convite e lá estava eu assinando contrato com a produtora do grupo, sendo informado que dali a uma semana já teríamos a pré-estreia numa cidade do sudoeste da Bahia: Jequié- cidade pequena e com pouca tradição teatral- sendo que nem o diretor, nem sequer a assistente de direção (Clarissa Rebolças), nem o iluminador responsável pela criação (Eduardo Tudella), iriam estar nessa apresentação para me instruir, me apresentar o espetáculo e me indicar os tempos, atmosferas e nuances da luz ao longo do espetáculo. Havia à minha disposição a planta de luz oficial que foi planejada para o espetáculo, mas não a planta real, aquela que após as negociações com os equipamentos técnicos disponíveis e as demandas prioritárias da peça, conseguimos executar; nem tão pouco o roteiro de operação da luz (a equipe estava habituada com o espetáculo e não fazia questão dessas "formalidades técnicas"). O que havia era um maço de anotações desencontradas, rabiscos e desenho que eu tive de decifrar, como a montar um quebra- cabeça, para chegar a algo satisfatório com auxílio da filmagem da peça, almejando montar um projeto condizente com a qualidade do espetáculo e com a expectativa que colocavam em minhas mãos ao iluminar um trabalho tão primoroso.

Eis que chega a grande estreia e, como era de se esperar, a luz da apresentação foi uma verdadeira sucessão de desacertos: falta de entrosamento, afinação e ângulos inadequados, o que demonstrava que a operação da luz estava muito aquém do que deveria ser. Fato constatado pela insatisfação bastante evidente do ator, ainda mais quando voltamos à capital baiana e o diretor me chamou para conversarmos sobre a minha desastrosa estreia.

Após explanar sobre a insatisfação do interprete e da insegurança que estava sentindo com a minha presença na equipe, e com as devidas cautelas que eu deveria ter nos próximos passos, combinamos que faríamos uma tarefa de casa: iríamos sentar juntos e assistir à gravação da peça, quadro a quadro, via DVD, para que ele pudesse amenizar as dúvidas que fossem possíveis naquele momento, já que não teríamos mais nenhuma oportunidade para ensaios gerais ou "algo que o valha".

Assim, após um café e meia dúzia de palavras, lá estava eu prostrado na frente de uma TV, tentando entender os rabiscos do roteiro de operação sob as indicações do Gil Vicente e pensando com os meus inquietos dedos: onde eu fui amarrar o meu bode?

O projeto de luz desse espetáculo foi desenvolvido pelo mestre da iluminação cênica baiana, Prof. Dr. Eduardo Tudella, e era riquíssimo em composições, nuances específicas para cada cena do espetáculo. Muitas vezes além de compor a visualidade do espetáculo, surgia, ora como composição de atmosfera, ora pontuando algum momento especifico; mas, sobretudo, a luz funcionava como personagem a jogar o tempo inteiro com o ator, numa atuação constante que necessitava da realidade do jogo cênico para acontecer com precisão. Assim sendo, carecia do suor da sala de ensaio, dos momentos errantes para descobrir a magia da cumplicidade em cena. Necessitávamos de tempo do bom dia, do café no copo descartável, das conver- 
sas triviais e risos soltos, das comparações com processos anteriores. Carecíamos de tempo, inclusive, para falar mal do diretor/ iluminador e das suas loucas proposições. Enfim, faltava o tempo da intimidade, da cumplicidade e da construção das relações que o processo de criação exige de quem se aventura a trabalhar com Teatro.

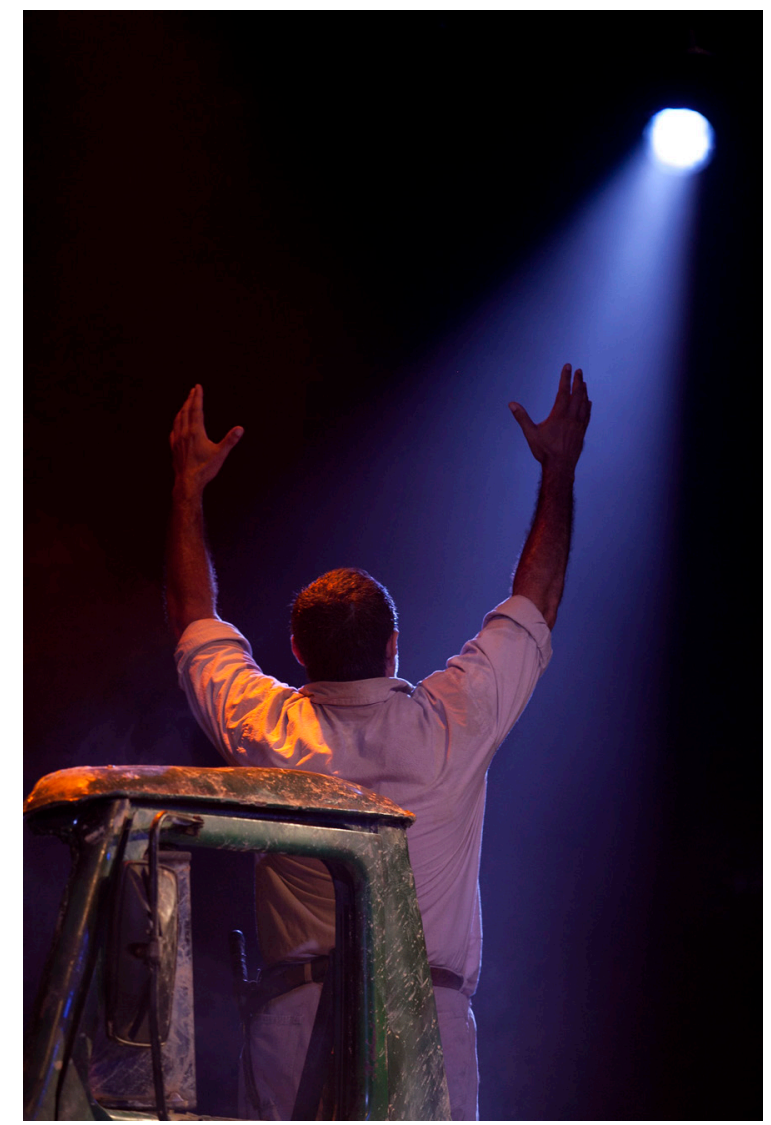

Sargento Getúlio. Foto: Adenor Gondim. Acervo pessoal.

Tínhamos muito: muitos prêmios ${ }^{7}$, muitos profissionais envolvidos, muitos anos de experiência em produções, muitas apresentações pela frente, embarques e desembarques e muitas expectativas com o projeto que se avizinhava. Mas em Teatro, aprendemos desde cedo, que mais é menos e vice-versa. Faltava o olho no olho e o frio na barriga compartilhado logo após o primeiro sinal que marca a entrada do espectador na sala e tudo tem que acontecer como planejado.

Mas isso eu só entendi ao longo das apresentações. Nesse início precisava dominar a técnica, a afinação, as composições, os tempos e, mais que tudo, adaptar a planta de luz projetada com mais de 70 refletores, a uma estrutura, agora, mais modesta possível, com aproximadamente 23 refletores, e conseguir, ainda que parcialmente, manter todos os efeitos solicitados pela encenação.

Daquela primeira e única reunião com o diretor ficou a certeza de que eu teria muito trabalho pela frente, e que precisava correr contra o tempo porque dali a mais duas semanas (26 de março de 2014) estaríamos desembarcando no Sul do país para

\footnotetext{
${ }^{7}$ Prêmios e Seleções de Sargento Getúlio - Prêmio Braskem de Teatro 2011: vencedor nas categorias melhor espetáculo e melhor ator (Carlos Betão), além de ter sido indicado nas categorias melhor direção (Gil Vicente Tavares) e melhor iluminação (Eduardo Tudella). $19^{\circ}$ Porto Alegre em Cena (2012). Festival Latino Americano de Teatro da Bahia (2012). Festival internacional de artes cênicas da Bahia (2012). Verão Cênico - mostra de teatro baiano (2012). Festival de Curitiba, mostra Fringe (2013). Prêmio Funarte Myriam Muniz de circulação (2013). Circulação Caixa Cultural (2013). Janeiro de Grandes Espetáculos (Recife, 2014). Palco Giratório - SESC (2014).
} 
a primeira apresentação do espetáculo no projeto de difusão das artes cênicas, promovido pelo SESC, na cidade de Joinville (SC).

Para início de conversa, devo esclarecer que, ainda que o SESC ofereça sempre o melhor que pode para a realização do projeto, nem sempre será o mais adequado às necessidades dos espetáculos. Como já era de se imaginar, tendo em vista a desigualdade econômica do território brasileiro e da grande falta de infraestrutura nos espaços teatrais, principalmente nas cidades do interior (que nem precisa fazer esforço aqui para detalhar as carências técnicas existentes), obriga as produções contratadas a fazerem um esforço extra para adequar o espetáculo às diversas possibilidades técnicas que encontrarão durante a realização do projeto.

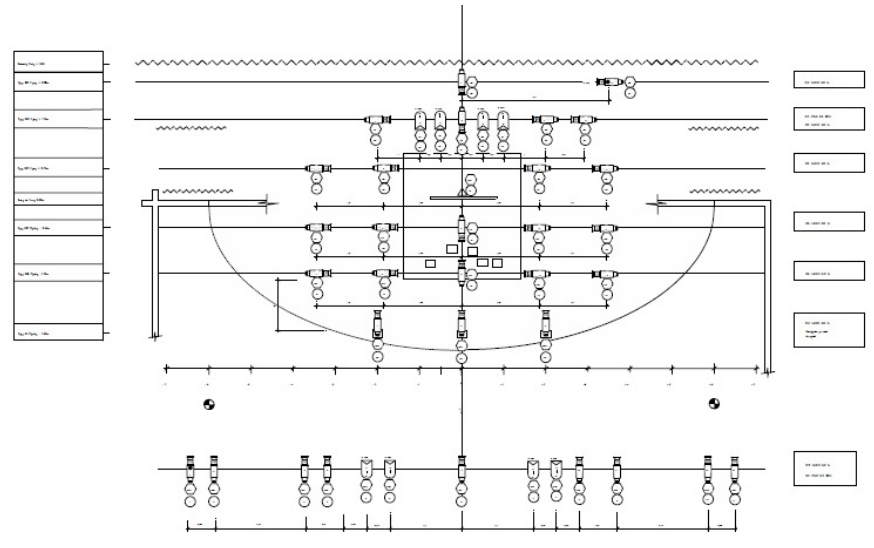

Planta1 - oficial

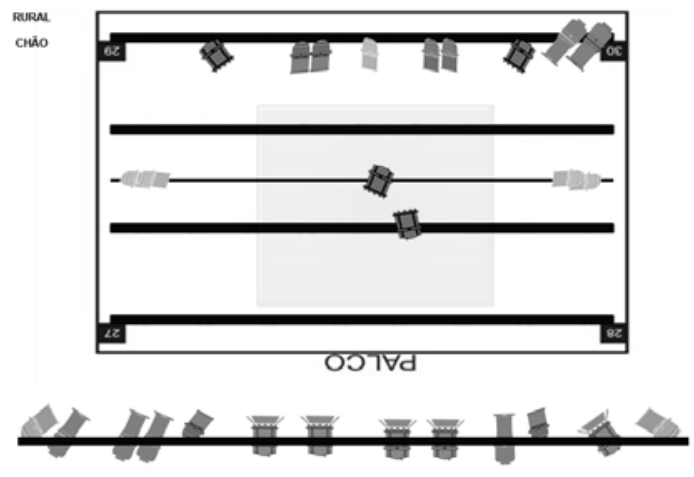

Planta2 - adaptada

\section{Coração nas pontas dos dedos}

Dito isto, vamos a nossa experiência no projeto: desembarcamos na cidade de Joinville no dia 26 de março e começamos a preparar a produção do espetáculo que, para minha sorte, foi em um teatro bem equipado - Teatro Juarez Machado, localizado no Centreventos Cau Hansen - e mais do que eu esperava e tinha projetado, funcionou como um belíssimo cartão de visitas. Nesta cidade fizemos apenas uma apresentação no dia posterior a nossa chegada, e ao consegui executar o projeto de luz que havia planejado depois de me debruçar por horas estudando e analisando a filmagem do espetáculo, estrei bem mais confiante, ainda que tivesse com o coração nas pontas dos dedos.

O êxito na apresentação me amparou e ajudou na desconfiança que o ator sentia em relação ao meu trabalho (saltei do grau -3 para o -1, ufa!), mas ainda tinha muito a desenvolver, pois, mesmo que tivesse funcionado muito do que delineamos, havia alguns erros pontuais e era visível a falta de harmonia e entrosamento entre nós. Contudo, de alguma forma, talvez por resignação, ele entendeu que fazia parte do processo e resolveu me dar uma colher de chá, mesmo que tenha pontuado cada momento de falta que cometi durante a apresentação.

Como adiantei no parágrafo anterior, a realidade técnica dos espaços cênicos para a apresentação dos espetáculos não são sempre favoráveis, sentimos esse im- 
pacto já na segunda apresentação do projeto na cidade de São Bento do Sul (SC), que, por não possuir um teatro, recebe os eventos cênicos no Centro Cultural Genésio Tureck, um antigo cineteatro, sem varas ou suportes para refletores e com uma péssima acústica (a impressão que tínhamos era a de estarmos dentro de um túnel, tamanha quantidade de reverberação dos sons quando eram emitidos).

Por não ter nenhuma estrutura técnica para montar a luz no auditório, o SESC dispôs de uma equipe de som e luz para realizarmos a apresentação neste e em outros "espaços alternativos", quando fosse necessário. Deste modo, foram elevadas algumas estruturas metálicas Q30, encima do palco, ao redor do cenário, para poder montar os refletores. Completando o equipamento com uma mesa Avolites 2048, ideal para shows musicais, não para teatro, com a qual o técnico não sabia como fazia gravações de cenas, costumeiramente, explicou, utilizava os canais individuais, sem composições. Ou seja, eu fiquei completamente "às escuras". Além de ter um equipamento nada adequado, teria que operar a luz no manual, sem as devidas cenas gravadas, em um auditório ruim e com um ator desconfiado.

No decorrer da montagem e das várias adaptações, o meu projeto de iluminação para o Palco Giratório já havia caído por terra ao ter que trabalhar com as ferramentas que tínhamos em mãos: no lugar de refletores Fresnel, lâmpada PAR64. No lugar de PC, PAR-64. Já para os refletores elipsoidal de 19 graus, tivemos que substituir por refletores PAR-64, também. Os únicos refletores que havíamos solicitado e estavam disponíveis era um par de elipso 25-50, e 2 PC que precisou passar por uma revisão para poder funcionar (que Dionísio me proteja, pensei). E imediatamente comecei a desenhar uma adaptação na planta para aquela estrutura e equipamentos disponíveis.

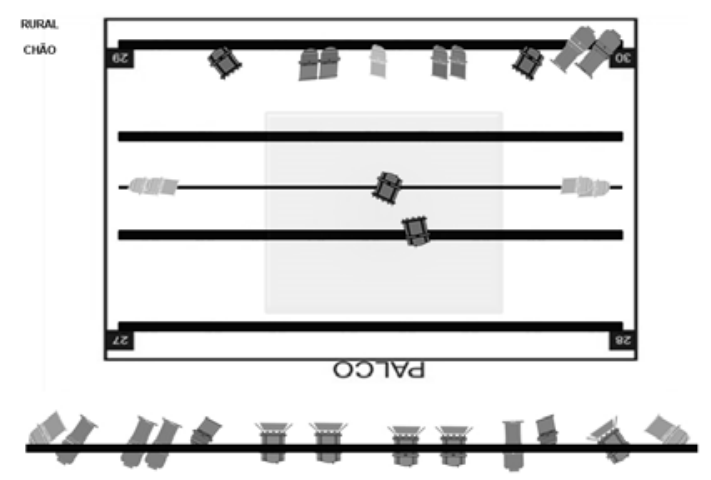

Planta2 - adaptada

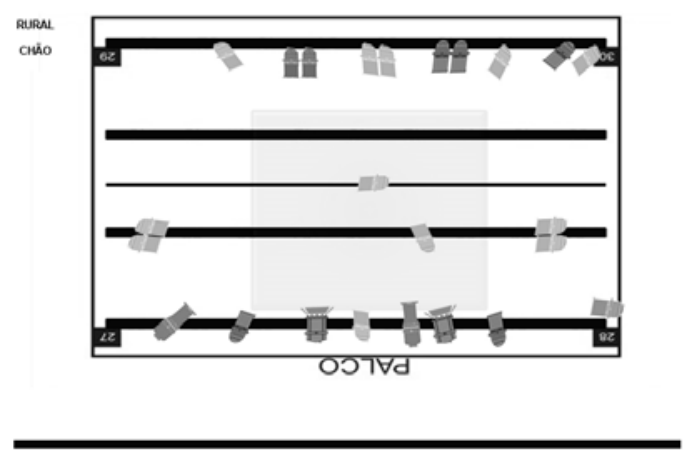

Planta3 - Q30

Deste modo, sem raciocinar duas vezes e acreditando que a adversidade nos une, procurei o ator e expus as condições técnicas que tínhamos, informando que precisaríamos de calma para que o espetáculo acontecesse. Que baixássemos o nosso grau de expectativas e aceitássemos o que estava posto, pois aquela apresentação em São Bento do Sul (SC), seria muito complicada. Não só para a iluminação, mas, sobretudo, para ele, que teria que domar os ecos do espaço. A iluminação, na condição que nos foi apresentada, se mostrava como o problema menos drástico daquele dia, porque o embate da sonoplastia, com a voz do ator e a reverberação do espaço 
era uma realidade dramática e carecia de mais atenção.

Bom, não posso afirmar que ele acatou as minhas sugestões ou se a demanda dele com as ondas sonoras foram realmente maior que a querela comigo, só sei que as maiores queixas dele nessa noite ao telefone com o diretor, após a apresentação, ficaram à luz do som no espaço, não sobre a luz do espetáculo que, por não ter altura suficiente na estrutura de Q30, quase o cozinhava vivo com o calor dos refletores PAR-64.

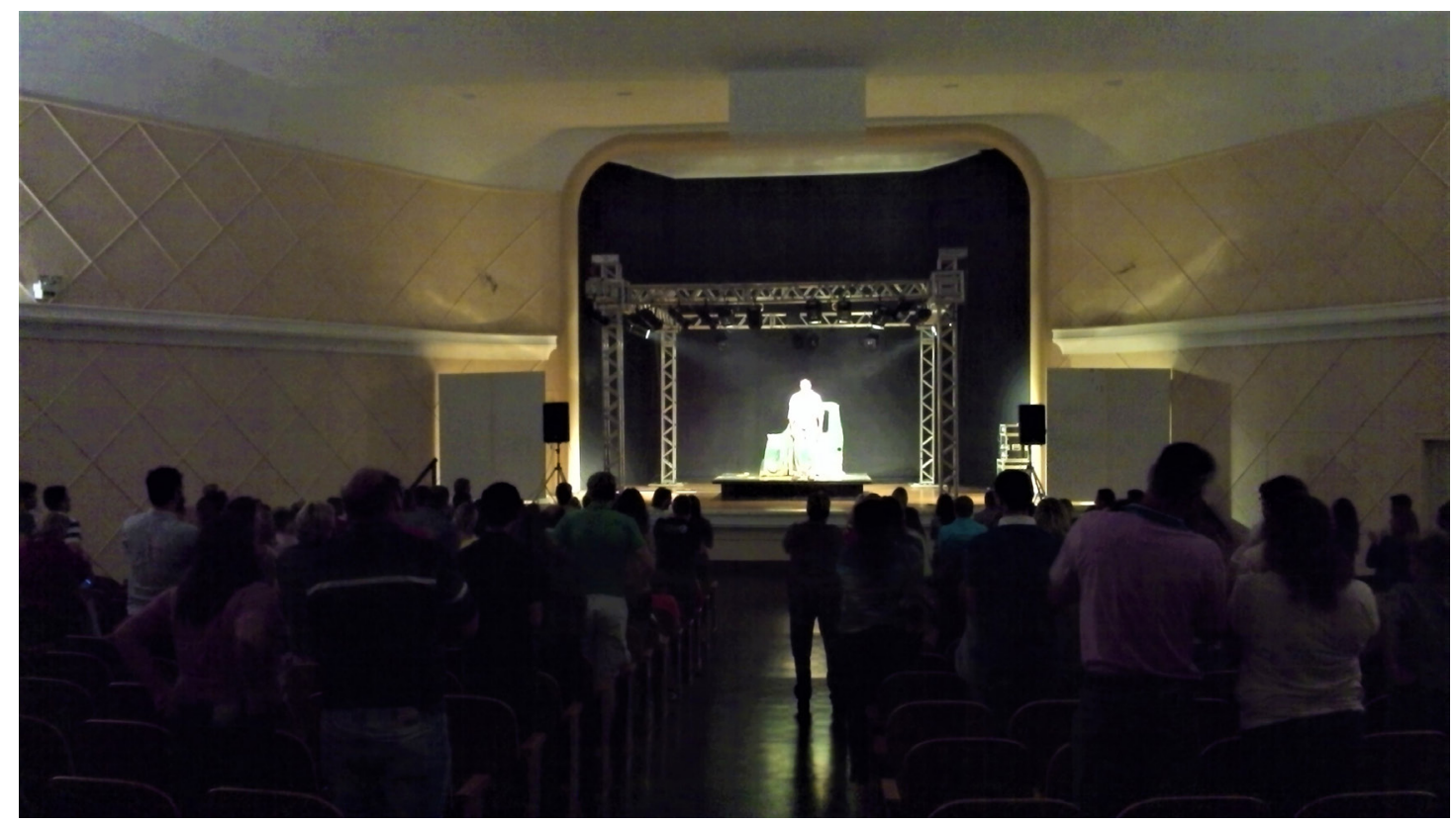

Sargento Getúlio

Centro Cultural Genésio Tureck. Arquivo pessoal.

Mas, se cada dia tem a sua agonia, a nossa só estava começando, pois ainda teríamos mais 41 agonias, digo, apresentações, distintas pela frente. Sendo que na primeira etapa da turnê - dois primeiros meses- dispúnhamos apenas de um dia para montagem, apresentação e desmontagem, já que no dia seguinte teríamos que pegar a estrada para chegamos a outros espectadores (entre os Estados o descolamento era feito de avião. Porém, entre as cidades de cada Estado nosso modal era uma Van).

A apresentação seguinte foi na cidade de Jaraguá do Sul (SC), dentro da unidade do SESC, espaço tecnicamente adequado para receber um espetáculo, e pelas suas dimensões - pequeno e aconchegante, com capacidade para pouco mais de 100 espectadores - serviu como uma luva para o espetáculo intimista que estávamos apresentando. Neste teatro, finalmente, puder ver o projeto que havia planejado funcionar com satisfação (ver planta2 adaptada). A execução da operação também mostrou avanços e indicava uma sintonia com os tempos do ator, das atmosferas, da contracena luz-personagem.

Se na minha percepção as coisas começavam a acontecer, faltava a avaliação de fora para analisar o andamento do espetáculo, que veio já na cidade seguinte, Blumenau (SC), realizada no Auditório Carlos Jardim - Fundação Cultural de Blumenau. Nesta apresentação, tivemos que contar com a estrutura de Q30 e com os refletores inadequados mais uma vez, para fazer o espetáculo funcionar dentro de um espaço cênico muito limitado e com sérios problemas estruturais. A sala era muito velha e 
malconservada, além de apresentar um claro descaso na manutenção dos equipamentos (palco com madeiras elevadas e pregos aparentes, varas de luz enferrujadas, tomadas sem funcionar, ventiladores quebrados, etc.), tivemos que contornar as adversidades e montar o espetáculo, contando, inclusive, com o atraso da equipe de luz, com a queima da lâmpada de um dos elipso e com a quebra de alguns canais na mesa que pararam de funcionar.

Apesar de todos esses contratempos técnicos, fizermos um bom trabalho. Porém, fomos informados, no dia seguinte à apresentação, que uma das colaboradoras do SESC havia entrado em contato com a produção do SESC (BA), relatando, dentre outras coisas, que o espetáculo tinha acontecido com êxito, ainda que demonstrasse uma evidente falta de entrosamento entre a equipe, o que não era uma inverdade, mas para uma equipe que lutava para se sintonizar, foi mais um motivo para fortalecer a insegurança do ator.

Este comentário foi narrado via mensagem de texto na manhã seguinte à apresentação pelo diretor do espetáculo (que estava em Salvador (BA), e por motivos operacionais não pode acompanhar o grupo neste projeto), me informando que o ator havia entrado em contato com ele para contar o que se passara na apresentação e me cobrar mais acertos, pois havia acreditado em mim, que era para eu cumprir o acordado e que não aceitaria que a qualidade do espetáculo fosse diminuída pelas minhas eventuais falhas de execução.

Caros leitores, essa foi a gota de limão que faltava para azedar o caldo de vez na relação entre eu e o ator, já que em nenhum momento ele havia conversado com a equipe sobre a apresentação e seus eventuais aborrecimentos. Não só da luz, mas também da sonoplastia, pois a moça que nos acompanhava na equipe (Júlia Salgado), se revezava na função de produtora executiva e operadora de som, sem nunca ter trabalhado na segunda função, até o início do projeto, e que, durante a apresentação, havia perdido o tempo de colocar uma das músicas, contribuindo para desestabilizar o ator por completo.

De repente, entre a ânsia de resolver o conflito, enfrentando ou fugindo, veio o estalo: nos faltava diálogo. Éramos um grupo de pessoas que se encontrava pela primeira vez e imediatamente havíamos criado, por diversos motivos, as barreiras a partir dos nossos pontos de vista individuais. Era preciso aceitar o ponto de vista do outro como positivo, fazendo com que as diferenças ficassem mais aguçadas, e fortalecer a ideia de conjunto, desse ambiente heterogêneo que é o Teatro, como nos lembra Peter Brook:

O elemento básico de qualquer peça é o diálogo, que supõe tensão e presume que duas pessoas não estejam de acordo. Temos aí o conflito; se é sutil ou manifesto, não importa. Quando pontos de vista se chocam, o dramaturgo é obrigado a dar a cada um deles um peso equivalente de credibilidade.... Um único ponto de vista, por mais forte que seja, empobrece o conjunto. (Brook, 1994, p. 35)

Deste momento em diante, como iluminador, precisei colocar uma luz de 1000w na relação interpessoal com o ator, ao escancarar a insatisfação recíproca e cobrar uma postura mais profissional enquanto equipe. Estamos no mesmo barco e era preciso remarmos juntos, ou, morreríamos afogados no nosso ego, na nossa vaidade, 
nas nossas cobranças pessoais. Era preciso trabalhar em equipe, juntos por uma causa maior que era o espetáculo, o projeto, o Teatro (nossa devoção). Precisamos estar irmanados nessa ideia para não perdermos o foco. Carecíamos de plugar as tomadas nas voltagens certas, para iluminar nossos sorrisos e curtir aquele momento, do contrário, nossa turnê seria uma verdadeira tragédia.

Já que a experiência tinha chegado ao limite, me interessei cada vez mais por todos os elementos que diretamente estavam relacionados com o espetáculo e, quando se parte por esse caminho, nos lembra Brook (1994), tudo o mais desaparece. Deixei claro, também, que eu e o restante da equipe, estávamos ali como coadjuvantes cientes de que nosso papel só existe para que ator principal reluza. Mas, convictos de que para ele brilhar em cena precisava de alguém para afinar a luz e acionar os botões certos na hora exata, e que ele podia contar conosco para isso acontecer. $\mathrm{E}$, mais, que o apoio e resignação dele seriam imprescindíveis para o sucesso do espetáculo no projeto.

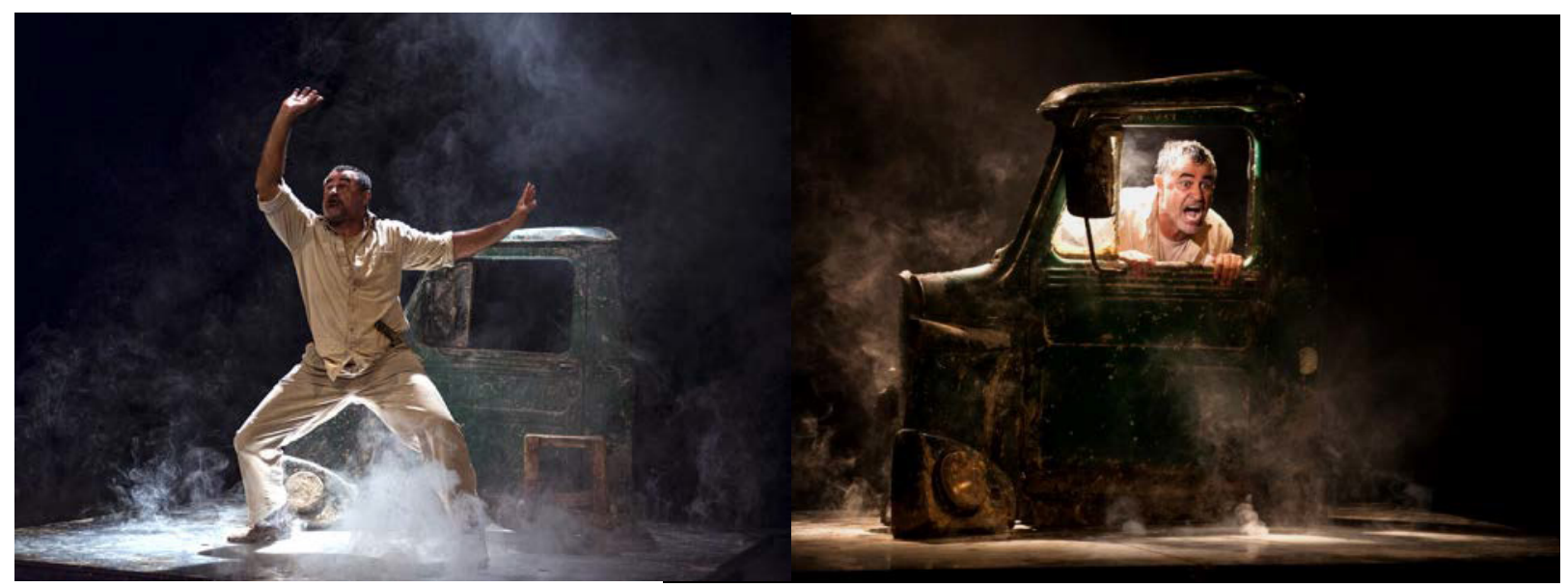

Sargento Getúlio ${ }^{8}$

Desse dia em diante tivemos outras pelejas: mesa de comando com defeito nas memórias e refletores queimados durante a apresentação, teatros sem refrigeração, salas completamente inadequadas para receber o projeto, como em Parati (RJ), onde tivemos que apresentar o espetáculo dentro da casa do falecido Paulo Autran, por falta de sala de apresentação - à época - dentre outros imprevistos que tivemos e conseguimos contornar. Mas se não tivéssemos conversado e usado nossas diferenças para fortalecer a equipe, unidos e em harmonia, muitas coisas não teriam acontecido, e nós, certamente, não conseguiríamos terminar o projeto com o êxito alcançado, felizes e até sentindo saudades dos momentos de crise que tivemos, cientes de que a crise e o conflito são o alimento do trabalho artístico.

Deste modo, empiricamente, constatei que o processo de aprendizado de um agente da cena - seja ele ator, diretor, iluminador, sonoplasta - é circular e feito de agenciamentos, isto é, interdependente uns dos outros numa cadeia que se desenvolve e se retroalimenta. Ou seja: ninguém educa ninguém, ninguém educa a si

${ }^{8}$ Fonte - http://www.sescmatogrosso.com.br/arsenal/galeria,1409,palco-giratorio-sargento-getulio-teatro-nu-ba.html 
mesmo, os homens se educam entre si, mediatizados pelo mundo ${ }^{9}$ - como preconiza Paulo Freire- ou, ainda, como entende Virginia Kastrup:

A aprendizagem não é e entendida como a passagem do não - saber ao saber, não fornece apenas as condições empíricas do saber, não é uma transição ou uma preparação que desaparece com a solução ou resultado. A aprendizagem é sobretudo invenção de problemas, é experiência de problematização. (Kastrup,1999, p. 207)

Em verdade, todo o processo de aprendizado durante os meses do projeto Palco Giratório só foi possível pelas constantes trocas de experiências com os companheiros que compunham a equipe do espetáculo, pelas confusões e percalços do trajeto; pelos improvisos e acasos descobrimos a verdadeira razão de ser do nosso trabalho, da segurança que tínhamos que depositar nos nossos pares de modo que - espetáculo pudesse acontecer, apesar da lâmpada queimada, apesar da mesa travada, apesar do B.O em cena aberta, apesar do "branco" do texto, apesar da música fora de hora, apesar dos risos e comentários fora de hora, apesar do cancelamento de uma das apresentações em Maceió (AL) -por problemas logísticos do SESC localapesar, e por todas essas diversas experiências que fazem parte do evento teatral, é que aprendemos que o conhecimento adquirido neste projeto só foi possível graças à arte do encontro, como nos lembra Grotowski no "Em Busca de um Teatro Pobre". E que é ela, no instante preciso e efêmero da sua existência, que possibilita o nosso verdadeiro aprendizado.

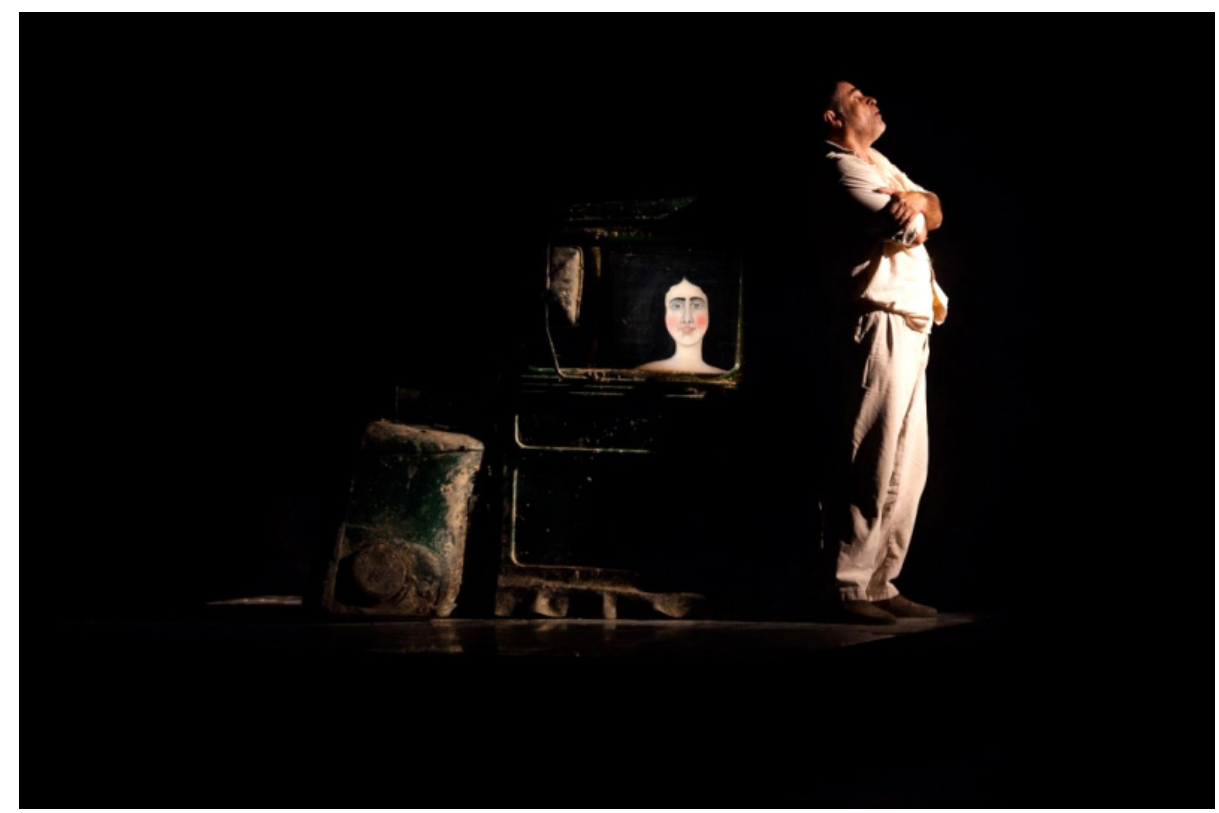

Sargento Getúlio ${ }^{10}$

Percebo, enfim, que corri um grande risco de ser mal interpretado, de que o ator (que muito admiro e que hoje posso dizer amigo), pudesse pedir meu afastamento da equipe e de conseguir um desafeto duradouro por conta da minha audácia. Mas aprendi desde muito cedo na minha formação como agente da cena, que é através do rompimento com os esquemas verticais, característicos da educação bancária, voltando à Freire (1994), que se realiza a prática da liberdade educadora. Ciente de

\footnotetext{
${ }^{9}$ Paulo Freire, 1987, p.39.

${ }^{10}$ Fonte - http://www.sescmatogrosso.com.br/arsenal/galeria,1409,palco-giratorio-sargento-getulio-teatro-nu-ba.html
} 
que não é possível alcançá-la fora do conflito, do embate de ideias, dos diversos pontos de vista e, principalmente, do diálogo que media toda ação artística e educacional, para que possa surgir um entendimento que supere a noção limitada que cada indivíduo tem da realidade.

Entendo, portanto, que no início dessa trajetória tínhamos uma realidade sem forma e com várias arestas e contratempos. No final, quando o círculo se fechou, essa mesma realidade pode ressurgir, de repente, dentro de um círculo de aprendizado que marcou nossa experiência no Palco Giratório. Só nesse momento a realidade se tornou uma coisa viva, concreta, e o verdadeiro significado do projeto veio à tona: aprender a aprender.

\section{Referências}

BROOK, Peter. Ponto de mudança. Rio de Janeiro: Civilização Brasileira,1994.

FREIRE, Paulo. Pedagogia do oprimido. Rio de Janeiro: Paz e Terra, 1987.

FREIRE, Paulo. Educação como Prática da Liberdade. Rio de Janeiro: Paz e Terra, 1994.

GROTOWSKI, Jerzy. Em Busca de um Teatro Pobre. Rio de Janeiro: Civilização Braาsileira, 1987.

KASTRUP, Virginia. A invenção de si e do mundo - uma introdução do tempo e do coletivo no estudo da cognição. Campinas-SP: Papirus,1999.

Recebido em: 20/11/2017

Aprovado em: 28/02/2018 